\title{
"I LIVE WITH DOUBLENESS": GÓTICO, FICÇÃO CIENTÍFICA E DISTOPIA EM FRANKISSSTEIN DE JEANETTE WINTERSON
}

Júlia Braga Neves (USP)

Recebido em 19 jan 2020. Júlia Braga Neves é doutora em Literatura e Cultura Aprovado em 18 mai 2020. Inglesas pela Universidade Humboldt de Berlim e pelo King's College, Londres. Desde 2019, atua como pós-doutoranda na USP, com financiamento da FAPESP. Seus interesses de pesquisa são voltados para literatura inglesa, literatura brasileira, literatura de viagem, a relação entre literatura e história, teorias queer e feminista. Lattes: http://lattes.cnpq. br/3595438360845230 Email: juliabneves@gmail.com

Resumo: Este artigo tem como objetivo analisar o entrelaçamento dos gêneros literários gótico, ficção científica e distopia em Frankissstein, romance de Jeanette Winterson, publicado em 2019. O foco da discussão será voltado para as representações do duplo, do trans e pós-humanismo em relação às construções do corpo, de gênero e de sexualidade. Argumenta-se que o romance de Winterson se utiliza de temas já abordados por Mary Shelley em Frankenstein, como a ciência, a discussão sobre a natureza do homem e a relação entre o homem e a natureza, para refletir sobre os desdobramentos dos avanços científicos e tecnológicos na inteligência artificial, e sobre as questões que dizem respeito à transsexualidade, feminilidade e masculinidade.

Palavras-chave: Jeanette Winterson; Gótico; Ficção Científica; Distopia; Teoria Queer. 
Abstract: This article aims to analyze the intertwining of gothic, science fiction and dystopia as literary genres in Frankissstein, a novel by Jeanette Winterson published in 2019. My discussion will focus on the representations of the double, of trans and posthumanism in relation to the constructions of the body, gender and sexuality. I will argue that Winterson's novel employs themes that have already been explored by Mary Shelley in Frankenstein, such as science, the discussion about the nature of man and the relation between men and nature, in order to reflect on the unfolding of scientific and technological advances in artificial intelligence. Moreover, my article will consider how these issues are associated with representations of transsexuality, femininity and masculinity in the novel.

Key words: Jeanette Winterson; Gothic; Science Fiction; Dystopia; Queer Theory.

\section{INTRODUÇÃO}

Publicado em 2019, Frankissstein: a Love Story, da escritora inglesa Jeanette Winterson, apresenta uma adaptação contemporânea do romance gótico de Mary Shelley, Frankenstein, de 1818. Trata-se de um enredo que entrelaça duas narrativas simultâneas: a história sobre a gênese do romance de Shelley pelo viés de sua biografia ficcionalizada, e a história sobre o médico transgênero Ry Shelley e do cientista Victor Stein, que é um pesquisador vinculado à Universidade de Manchester e realiza experimentos com inteligência artificial. No entanto, essa pesquisa de Victor é apenas sua versão oficial. Em seu laboratório subterrâneo, ele desenvolve um projeto secreto com cérebros humanos que não poderia passar pelos trâmites da comissão de ética: o cientista busca aprimorar a 
inteligência artificial a fim de eliminar a morte e poder realizar o upload da consciência de um indivíduo como dados que podem ser armazenados em qualquer corpo.

A ideia de Victor Stein ecoa justamente os temas abordados no Frankenstein de Mary Shelley: a discussão sobre a separação do corpo e da mente; o mito do Prometeu; os limites e os perigos dos avanços científicos e a possibilidade de transformar a morte em vida. Os paralelos criados entre este romance gótico do século XIX e a história de Ry e Victor, que se passam num futuro não muito distante, mostram que, apesar da distância temporal, as questões filosóficas, morais e éticas que envolvem a relação dos humanos com a natureza, com a ciência e com a tecnologia, a ambição de transgredir e romper com a morte e a possibilidade de intervir na evolução humana são temas que persistem no mundo atual.

As críticas publicadas na imprensa são quase unânimes na associação óbvia do romance de Winterson com o gótico (cf. CHARLES, 2019; KELLOGG, 2019; SHEPPARD, 2019; WILLIAMS, 2019). Porém, como acontece em quase toda a obra literária de Winterson, Frankissstein não pode ser rotulado sob um único gênero literário. Sam Byers (2019), do jornal britânico The Guardian, não cita diretamente o gótico, mas relaciona o romance com o "Romantismo científico" e o descreve como uma fusão da "hiperinvenção da ciência nociva com um realismo histórico bastante sugestivo, balanceado por trechos hilários e quase indecentes" 12 (grifo meu); este último aspecto

1 "the hyperinvention of rogue science with deeply evocative historical realism balanced by hilarious, almost bawdy set pieces".

2 Todas as traduções dos textos em língua inglesa são minhas, inclusive aquelas retiradas de Frankissstein. 
também é elencado por Charles (2019), que percebe elementos da comédia em Frankissstein.

O termo "realismo histórico" utilizado por Byers pode ser excessivo, ainda que o romance, de fato, represente eventos, lugares e figuras históricos. O enredo se passa num mundo pós-Brexit, onde o "nacionalismo é ascendente"3 (WINTERSON, 2019, p.110); a Fundação Alcor, que desenvolve pesquisas com a extensão da vida humana a partir de congelamento de corpos em Arizona, é real, bem como a história sobre as origens de Frankenstein no Lago Léman, na Suiça, em 1816, quando os Shelley viajaram acompanhados pelo poeta Lord Byron e sua amante, a meia-irmã de Mary, Claire Clairmont, e pelo médico John Polidori, autor de The Vampyre (1819), romance gótico também concebido nessa mesma viagem. Outras figuras históricas são transformadas em personagens, como os matemáticos Alan Turing, I.J. Good e Ada Lovelace, e, até mesmo, os atuais presidentes dos Estados Unidos e do Brasil, Donald Trump e Jair Bolsonaro. Ambos os políticos são citados como exemplos da proximidade do perigo no futuro, que poderia ser hoje mesmo. Desconfiada sobre as projeções futurísticas da inteligência artificial promovidas por Victor Stein, a jornalista Polly D. tenta obter informações de Ry Shelley sobre a sua pesquisa:

Eu não confio na maneira pela qual a IA [Inteligência Artificial] está sendo vendida para nós. As pessoas não estão por dentro da conversa, muito menos das decisões. Vamos acordar um dia e o mundo não será o mesmo.

3 "Nationalism is on the rise". Todas as traduções de Frankissstein: a Love Story são minhas, pois ainda não havia tradução em português do romance no momento de escrita deste artigo. 
Essa manhã pode ser qualquer manhã, acho. Pode ser o colapso climático. Pode ser nuclear. Pode ser Trump ou Bolsonaro. Pode ser 0 conto da aia $^{4}$ (p.98)

Para Polly D., a inclusão de robôs desenvolvidos a partir da inteligência humana, e uma virada tecnológica repentina que mais pode marginalizar que integrar são questões que são promovidas como futurísticas, mas que estão no horizonte do presente. Como discutirei nas próximas páginas, é o desdobramento dos avanços tecnológicos almejados pelos trans- e pós-humanistas e a falta de transparência em pesquisas científicas realizadas atualmente que constituem o aspecto distópico de Frankissstein. A convergência do gótico com a distopia, refinada pelo humor e pela historicidade do romance, toca em questões sociais e políticas relacionadas também a gênero, sexualidade, armazenamento de dados e com a débil regulamentação das pesquisas que envolvem bioética, principalmente pelos países com maior poder econômico.

Apesar de serem esses os temas centrais no romance de Winterson, há de se considerar também o subtítulo do romance, a Love Story, que é esquecido pela crítica. Sim, Winterson conta também histórias de amor: a de Mary Shelley com o seu marido Percy Bysshe Shelley; a trágica experiência maternal de Mary Shelley, que perdeu três filhos durante o seu matrimônio; e, finalmente, a história de amor entre os personagens Ry Shelley e Victor Stein. Como em The Passion (1987), Sexing the Cherry (1989) e Written on the Body (1992), as relações de amor são

4 "I don't trust the way Al is being sold to us. People aren't in the conversation, let alone the decisions. We're going to wake up one morning and the world won't be the same.

That morning could be any morning, I say. It could be climate breakdown. It could be nuclear. It could be Trump or Bolsonaro. It could be The Handmaid's Tail." 
conturbadas, mas possuem forças descomunais. Enquanto o amor de Mary e Percy Shelley a ajuda a superar as mortes de seus filhos e a ignorar as traições de seu marido com sua meia-irmã Claire Clairmont, o caso amoroso entre Ry Shelley e Victor Stein faz com que o primeiro participe ativamente de seus experimentos ilegais com o fornecimento de membros de corpos humanos, como braços, pernas, mãos e o cérebro do matemático I.J. Good.

Meu artigo tem como objetivo refletir sobre as afinidades textuais entre o gótico e a distopia, discutindo a imagem do duplo no gótico e as tendências trans e pós-humanistas em relação às representações de gênero e sexualidade no romance. Conhecida por sua temática lésbica e feminista em sua literatura, Winterson explora, em Frankissstein, o vínculo entre ciência e tecnologia com o corpo, bem como os perigos dessa aliança num contexto em que a extrema direita ganha força no cenário político internacional. Se a imortalidade e o aprimoramento da espécie humana estivessem no horizonte de um futuro próximo, estaria a sociedade preparada para lidar com essa revolução? Quais são as consequências éticas e morais desses avanços científicos e tecnológicos e a quem elas beneficiariam?

\section{O GÓTICO}

Segundo Amy Cartwright (2005, p.5), um dos elementos compartilhados pelo gótico e pela distopia como gêneros ficcionais é o fato de que ambos retratam problemas de cunho moral, psicológico ou social, principalmente quando a temática central está voltada para o corpo humano. Cartwright afirma que tanto o gótico quanto a distopia podem representar "os monstros e duplos, 
os fragmentos e labirintos, e lugares escuros", além de "colocar em primeiro plano os corpos atormentados, torturados e deturpados que povoam essas narrativas." 5 Além desses elementos, pode-se compreender o uso do sobrenatural e do fantástico como meios para construir mundos ficcionais que causam estranhamento na representação da realidade, transgredindo os padrões morais e expressando ambivalência no potencial crítico do texto ficcional (cf. SMITH, 2007, p.3; CLAEYS, 2010, p.109).

No romance de Winterson, as imagens do duplo são essenciais para a fusão de uma ficção científica distópica e o gótico. Conforme apontado por Smith (2007), o uso do duplo na literatura gótica "é uma indicação clara da internalização do 'mal'"' (p.94), simultaneamente revelando e escondendo comportamentos ou valores que não são aceitos no âmbito social. Em Frankenstein, de Mary Shelley, o monstro abjeto criado pelo cientista Victor Frankenstein é natural porque fora criado a partir de membros humanos, porém, é uma aberração porque fora produzido artificialmente pelo médico, o que também evoca a ideia de que o monstro é real e, ao mesmo tempo, irreal. Esta última interpretação sugere que Victor Frankenstein e seu monstro são, na verdade, duas metades do mesmo 'eu', que comportam o bem e o mal do ser humano (cf. BLOOM, 2007, p.91-96).

Em Frankissstein, Winterson emprega o elemento do duplo gótico, mas o contextualiza em discussões contemporâneas

5 "The monsters and doubles, the fragments and labyrinths, and the dark places of Dystopian Gothic novels resonate with both traditions and foreground the tormented, tortured and twisted bodies which populate these narratives."

6 "The Gothic's use of doubling is a clear indication of the internalisation of 'evil"" 
referentes a identidades não-binárias, ao pós-humanismo e à não-linearidade temporal. Muitas vezes, esses duplos são desconstruídos nos parâmetros da teoria queer, como modos de contestar identidades sexuais e de gênero binárias e de afirmar a própria indefinição identitária (cf. JAGOSE, 1996, p.1-3) ou questionar a historicidade de discursos e normas na sociedade (cf. BUTLER, 1993, p.228). Ry Shelley exemplifica um duplo queer do romance de Winterson, pois ele é um personagem transgênero, que alega que o "duplo é a verdade mais próxima para mim"7 (WINTERSON, 2019, p.119). O masculino e feminino que constituem a identidade de Ry são questões que ele se sente obrigado a explicar em âmbito social, pois a ambiguidade de gênero de seu corpo muitas vezes é percebida como uma ameaça, embora a promessa de revolução científica e tecnológica da inteligência artificial tente mostrar o contrário, como veremos na próxima seção.

A não-linearidade temporal do romance também reflete o duplo de Winterson, conferindo ao enredo uma estética fragmentária, muito comum na literatura pós-modernista e da própria Winterson. Não se trata aqui de uma simples duplicidade entre passado e futuro, mas das dicotomias presente-passado e presente-futuro, conforme a explicação de Victor Stein: "O oposto do passado é o presente. Qualquer um pode viver num passado que já foi embora ou num futuro que não existe. O oposto das duas posições é o presente." ${ }^{\prime \prime}$ (p.199) Esse esclarecimento de Stein retrata a própria temporalidade

7 "Doubleness is nearer to the truth for me."

8 "The opposite of the past is the present. Anyone can live in a past that is gone or a future that does not exist. The opposite of either position is the present." 
do romance, pois o leitor é inserido em diversas camadas temporais; contudo, todas elas convergem no presente, que pode ser o próprio momento da leitura.

Enquanto o primeiro capítulo se passa em 1816, narrando a viagem de Mary Shelley no Lago Léman e a gênese de Frankenstein, o próximo dá um pulo para o século XXI num evento sobre inteligência artificial em Memphis, onde são introduzidos os personagens Ry Shelley, Ron Lord e Claire. Na conversa entre os três, Ry comenta que a conferência Tec-X-Po está sendo realizada em Memphis por conta do romance Frankenstein, pois a cidade fora fundada em 1819 e o romance de Shelley, publicado em 1818, evidenciando os duzentos anos de idade de ambos. Essa afirmação nos leva a compreender que a história não se passa no futuro, mas no nosso próprio presente histórico. No entanto, o cenário composto por sexbots, como a robô Sophia que obteve cidadania na Arábia Saudita e "possui mais direitos que qualquer mulher saudita", e a ideia de que "a raça humana não é o melhor resultado possível"10 (p.74) e, por isso, deve ser superada, criam um cenário futurístico que causa estranhamento ao nosso próprio presente.

A construção futurística do presente também é formada pela frequente referência às crises políticas atuais, como o Brexit e a ascensão da extrema direita. Em Frankissstein, a saída do Reino Unido já foi finalizada, acabando com oportunidades de emprego no País de Gales e deteriorando as perspectivas de desenvolvimento desse país (p.50; p.225). As consequências da crise política do Brexit descritas por Winterson são, de fato, previsões para a região,

9 "She has more rights than any Saudi woman." (Grifo no original)

10 "The human race is not a best possible outcome." 
tendo em vista que o País de Gales conta com o financiamento anual da União Europeia destinado a planejamento urbano, construção, educação, desemprego e agricultura.

O romance leva o leitor a múltiplas temporalidades que são entrelaçadas de forma desordenada: passamos por 1818 (ano da visita de Mary Shelley ao seu personagem Victor Frankenstein no manicômio), 1819 (o luto de Mary Shelley pela morte de seu terceiro filho em Roma e a sua gravidez do único filho que sobreviveria), 1928 (a infância do matemático I.J. Good que teria sido o mentor de Victor Stein), 1938 (ano em que Good se formou em matemática na Universidade de Cambridge), 1941 (a atuação de Good como matemático na Segunda Guerra Mundial sob a orientação de Alan Turing), voltamos para 1822 (ano da morte de Percy Shelley) e para 1824 (a narrativa de um suposto encontro entre Mary Shelley e Ada Lovelace, filha de Lord Byron). Todos esses eventos do passado são intercalados com capítulos que se passam no final da década de 2010 e no início da década de 2020, ainda que os anos não sejam explicitados.

O jogo temporal de Winterson também está associado ao duplo da realidade-ficção, que é uma temática tratada durante toda a narrativa. Em quase todos os capítulos, há questionamentos sobre o que seria a realidade e a sua relação com o ficcional. $\mathrm{Na}$ epígrafe de um dos capítulos, Winterson reproduz um trecho da crítica publicada em 1818, na Edinburgh Magazine, sobre Frankenstein: "Nunca houve uma história mais louca imaginada, até agora, como quase todas as ficções de sua época, [a narrativa] tem um ar de realidade incorporada a ela." ${ }^{11}$ (p.53) Como no

11 "There never was a wilder story imagined, yet, like most of the fictions of this age, it has an air of reality attached to it." 
romance de Mary Shelley, Frankissstein reverbera a fusão do fantástico e do real, no sentido de que a narrativa ora aproximase de uma realidade do presente histórico e ora distancia-se dela, como se os acontecimentos políticos, sociais e históricos narrados possam ser apenas fragmentos de uma fantasia.

Quando Ron Lord apresenta ao público as suas sexbots, que são preferivelmente alugadas pelos seus usuários, ele explica o porquê da procura das robôs para satisfazer os desejos sexuais masculinos: "O que nós oferecemos é uma vida fantasia, não vida real." ${ }^{\prime 2}$ (p.46). O presente futurístico representado com a tecnologia é a possibilidade de satisfazer os desejos mais exóticos e extraordinários com o objeto artificial. Porém, o romance de Winterson questiona quais seriam os limites éticos e morais da ciência e da tecnologia na realização desses sonhos com a concepção de realidades artificiais. Por um lado, Ry é um indivíduo que se utilizou dos avanços científicos e tecnológicos para mudar o seu próprio corpo, pois ele se submeteu à cirurgia de mudança de sexo e ao tratamento hormonal para se tornar um homem trans. Por outro, o projeto de Victor Stein de conservar a consciência humana a partir da transferência de dados com o intuito de alcançar a imortalidade envolve o dilema ético de como escolher quem poderá viver eternamente e de como seria uma vida sem a morte.

O último aspecto do gótico a ser discutido refere-se aos espaços representados no romance, que remetem às "ruínas, castelos, [...] formas de monstruosidade e de insanidade"13 
(SMITH, 2007, p.4) que são comuns na literatura gótica. Por exemplo, o personagem de Mary Shelley, Victor Frankenstein, encontra-se internado no manicômio de Bedlam, localizado em Londres, que no início do século XIX fora alvo de diversas críticas por conta da precariedade de suas instalações, pelo tratamento de seus pacientes e por casos de corrupção em sua administração. 0 hospital "mal está pronto e, onde está pronto, deixa a desejar", pois não há vidros nas janelas dos pisos superiores e tampouco há meios de aquecimento para os pacientes, que "estão com frio, famintos, raivosos e desolados." ${ }^{14}$ (WINTERSON, 2019, p.175). Nessa instituição, Victor Frankenstein ganha vida e recebe as visitas de Capitão Walton, narrador de Frankenstein, e da autora, Mary Shelley. Nessa narrativa, que se passa em 1818, o narrador em primeira pessoa é identificado como Sr. Wakefield e sabe-se somente que ele é um funcionário, provavelmente um médico, de Bedlam. ${ }^{15}$ Capitão Walton, uma figura "muito conhecida para a nação - algo como um herói"16 (p.179) devido às suas viagens para explorar a Passagem do Noroeste e a Antártica, é quem conta a história de Victor Frankenstein ao Sr. Wakefield.

Quando o Sr. Wakefield pergunta a Victor Frankenstein qual é a sua história, ele responde: "Esse é o dilema. [...] Eu não sei se sou o narrador ou a narrativa"17 (p.194). Mary Shelley é então convidada para tentar resolver o problema. Durante sua visita, 14 "The new hospital is scarcely ready, and where it is ready, it is wanting. [...] The inmates are cold, hungry, angry or desolate."

15 É possível que esse personagem seja baseado na figura do inglês Andrew Wakefield, que foi proibido de atuar como médico no Reino Unido devido às suas condutas antiéticas na realização de pesquisas para comprovar a relação da vacina contra sarampo com a doença de Crohn. Atualmente, ele atua como ativista contra vacinas nos Estados Unidos (cf. MEIKLE e BOSELEY, 2010).

16 "Captain Walton is well known to the nation - something of a hero".

17 "This is the dilemma. [...] / do not know if I am the teller or the tale." (grifo no original) 
Frankenstein pede que ela o desfaça (“Unmake me"): "Eu sou o monstro que você criou. Eu sou a coisa que não pode morrer - e eu não posso morrer porque eu nunca vivi"18 (p.214). Frankenstein conta a Shelley que, ao invés de se perder nas geleiras, conforme o final de seu romance, ele acabara naquele manicômio, e que seu monstro ainda o persegue. A autora e o seu personagem discutem a sua narrativa e Frankenstein admite que ele e a sua criatura são a mesma pessoa.

No romance de Winterson, o encontro de Mary Shelley com Victor Frankenstein confirma a leitura de que o cientista e o seu monstro são um único indivíduo, refletindo a discussão da cisão do "eu" entre o bem e o mal, o corpo e alma. Enquanto a obra de Shelley reverbera os debates filosóficos de seu tempo sobre a natureza do ser humano e a divisão entre corpo e alma, a narrativa de Winterson sobre Mary Shelley e Victor Frankenstein em Bedlam implica a duplicidade entre realidade e ficção, autor e personagem. A consolidação de Frankenstein como um clássico da literatura, que obteve sucesso com suas inúmeras adaptações para o cinema e a televisão, é o que mantém a vitalidade de Victor Frankenstein e o seu monstro; estes não precisam de um corpo para estarem vivos, pois já existem na imaginação da cultura ocidental, da mesma forma que Mary Shelley é considerada canônica em sua criação. Winterson sugere, portanto, que a imortalidade reside no potencial de transgressão de uma criação, quando ela se torna um legado histórico, ao invés da pura continuidade da vida contida na materialidade do corpo.

O debate sobre a divisão entre o corpo e a alma e entre o bem 18 "I am the monster you created [...]. I am the thing that cannot die - and I cannot die because I have never lived." 
e o mal é retomada novamente na linha narrativa do século XXI. Victor Stein é retratado como um cientista poderoso, atraente, ambicioso e prepotente, que está disposto a romper com todas as normas para atingir o seu objetivo. Em sua palestra na renomada Royal Society, em Londres, ele defende que as limitações físicas do corpo humano serão desprezíveis com o avanço da inteligência artificial: "Robôs conseguirão muito do que os humanos conseguem hoje em dia. Inteligência - talvez até a consciência - não será mais dependente do corpo"19 (p.73). Para Stein, o corpo e a mente são cindidos ao ponto da última não depender do primeiro; a imortalidade será alcançada, de acordo com suas ideias, a partir do momento em que se possa transferir os dados cerebrais de um indivíduo para o computador, para que eles sejam inseridos em qualquer objeto - um robô, uma mão, uma perna, uma cabeça ou um animal - que possa viver eternamente.

Se a obstinação, a arrogância e o projeto mirabolante de Stein manifestam-se como características negativas, que podem causar antipatia ao leitor de Frankissstein, sua virtude é apresentada em sua relação com Ry. Ao contrário do romance de Mary Shelley, no qual a monstruosidade reside principalmente na aparência física do monstro criado por Victor Frankenstein, na versão de Winterson, pode-se dizer que a loucura, o desespero e o horror estão situados na própria ambição humana, que ela sugere fazer parte da nossa natureza.

Não se sabe se Victor Stein alcança o seu objetivo de criar um robô a partir da transferência de dados do cérebro de I.J. Good e, com isso, revitalizar a genialidade e consciência do matemático num

19 "Robots will manage much of what humans manage today. Intelligence - perhaps even consciousness - will no longer be dependent on a body." 
corpo qualquer. No entanto, sua tentativa causa um apagão geral na cidade de Manchester, que é representada, principalmente, por seus túneis subterrâneos, onde fica o laboratório de Stein. Esses túneis, de fato, existem em Manchester e foram construídos em segredo na década de 1950 para o funcionamento do governo britânico em caso de ataque nuclear.

A ficcionalização de Winterson desse espaço associa a monumentalidade histórica do bunker com tecnologia de ponta. Em sua primeira visita ao laboratório de Stein, Ry mostra-se temeroso enquanto conta os degraus que o levam para um local cada vez mais profundo, observando com curiosidade a maneira pela qual os porões de Manchester são surpreendentemente secos, os cabos, fios, tubos de vácuo e válvulas expostos nas paredes. Ry e Stein atravessam diversas portas até chegarem a uma porta de aço que leva para outro ambiente escuro, composto por uma janela de vidro reflexivo, que só permite a visão externa, pela qual Ry tenta enxergar:

Pela janela, concreto aparente. Uma lâmpada. Luzes dos monitores reluzindo estranhamente pelo gelo seco que enche o espaço. Consigo ver no termômetro da parede de fora que o interior é mantido um pouco acima do congelamento. Então, percebo movimento. Através da neblina gelada. Correndo em minha direção. Através do vidro. Quantas? Vinte? Trinta? ${ }^{20}$ (p.168)

Quando Stein acende as luzes, Ry pensa que são tarântulas,

20 "Through the window, bare concrete. Light bulb. Monitor lights glinting weirdly through the dry ice that fills the space. I can see from the thermometer on the outside wall that inside is kept just above freezing. Then I notice motion. Through the icy fog. Running towards me. Towards the glass. How many? Twenty? Thirty?" 
mas aterroriza-se ao ver "[m]ãos. Em forma de espátula, cônicas, largas, cabeludas, simples, manchadas. As mãos que trouxe para [Stein]" moviam-se rapidamente por todos os lados, "[u]ma caminhava usando seu mindinho e o dedão, os dedos do meio levantados para cima, curiosos e especulativos, como antenas"21 (s/p). A descrição do ambiente labiríntico articulada com a imagem de membros de corpos humanos avulsos movimentandose aleatoriamente constroem o universo gótico do estranho, do inquietante e do horror, enquanto a temática do uso da inteligência artificial como meio de incrementar a espécie humana e, consequentemente, eliminar a morte são elementos que conferem à narrativa o seu aspecto distópico associado à ficção científica, que serão discutidos na próxima seção.

\section{DISTOPIA, FICÇÃO CIENTÍFICA E IDENTIDADES QUEER}

As duas formas literárias, distopia e ficção científica, são frequentemente associadas por críticos, principalmente quando o debate é voltado para literatura produzida a partir do século XX. Para Robert Scholes e Eric Rabkin (1977), as obras de Aldous Huxley e de George Orwell marcaram a ficção distópica de língua inglesa ao enfatizar as repercussões sociais do avanço tecnológico e científico, por "pressupor que os processos tecnológicos e biológicos estão além do controle governamental e que vão moldar efetivamente a vida humana, independente de um sistema nominal de governo." ${ }^{22}$ (Apud ALDRIDGE, 1984, p.66) No romance de Winterson, essas 21 "Hands. Spatulate, conic, broad, hairy, plain, mottled. The hands I had brought him. Moving. [...] One walked using its little finger and thumb, the mid-fingers upwards, curious and speculative, like antennae."

22 "to assume that technological and biological processes have got beyond governmental control and will effectively shape human life regardless of the nominal system of government." 
questões são articuladas pelo trans- e pós-humanismo e também pela possibilidade de a inteligência artificial extinguir, nas palavras de Victor Stein, "o mundo de rótulos - e isso inclui binários como masculino e feminino, negro e branco, rico e pobre." ${ }^{23}$ (WINTERSON, 2019, p.79)

Enquanto o transumanismo promove a ideia de que os seres humanos devem ser aprimorados a partir da engenharia genética, tecnologia da informação e inteligência artificial a fim de garantir maior longevidade e qualidade de vida (cf. BOSTROM, 2005, p. 202-203; HALL, 2017, p.3-24), o pós-humanismo pode ser considerado um corolário dessa premissa, implicando "a simbiose do ser humano com as próteses tecnológicas", que antecipa "o futuro de outra espécie de corpo, nas interfaces do humano e do maquínico" (SANTAELLA, 2007, p.130). Nas teorias feministas e queer, as intervenções médicas ou tecnológicas no corpo podem ser entendidas como uma maneira de superar o feminismo tradicional centrado no sexo feminino e em sua função reprodutora e também como uma forma de contestar o binarismo identitário que define masculino e feminino, hetero- e homossexual (cf. HARAWAY, 2006; HALBERSTAM e LIVINGSTON, 1995, p.1-20). Essa é justamente a promessa de Victor Stein, a partir do momento em que a consciência humana possa ser separada de seu corpo.

Para Pearson et al., a teoria queer e a ficção científica convergem no sentido em que elas permitem imaginar "um futuro que abre, ao invés de impedir, possibilidades de tornar-se real", sendo a ficção científica um gênero relevante para "[explorar] essas possibilidades, 
bem como interrogar as consequências das sociedades e dos futuros"24 que condicionam as vidas de sujeitos não-binários. Em Frankissstein, o trans- e pós-humanismo estão claramente associados às transformações nas percepções epistemológicas e ontológicas referentes a gênero e sexualidade, não somente pelo fato de Ry ser transgênero, mas pelas próprias representações de masculinidade e feminilidade no romance.

Um exemplo são os sexbots criados pelo galês Ron Lord, dono de uma fábrica no País de Gales que produz robôs mulheres, que possuem três buracos de entrada e cujas vaginas vibram com a penetração. A ideia de fabricar sexbots surgiu quando Ron estava de férias na Tailândia, depois de um divórcio conturbado e um lucro de sorte num investimento em Bitcoins. Durante uma tempestade elétrica no país asiático, Ron teve de dispensar as prostitutas tailandesas porque havia colocado um piercing em seu pênis como pagamento de uma aposta e estava com medo de que o seu falo fosse atingido por um raio. Aterrorizado em seu quarto, Ron conta ter sido agraciado com uma visão:

Eu vi exércitos de homens solitários caminhando por uma estrada arruinada. Homens com suas cabeças baixas e suas mãos em seus bolsos. Ninguém estava falando. Cada um deles caminhava sozinho.

Então, vindo em direção aos homens, de repente, pela mesma estrada arruinada, estavam todas aquelas meninas bonitas. Meninas que nunca

24 "[...] a future that opens out, rather than forecloses, possibilities for becoming real [...]. We begin to understand the importance of [science fiction] as a genre for exploring these very possibilities, as well as for interrogating the consequences of societies and futures in which conditions render the lives of many unlivable-sometimes in unbearably literal ways." 
envelheceriam ou adoeceriam. Meninas que sempre diriam sim e nunca diriam não.

E no céu estava a lua, grande como um Bitcoin, e eu sabia que eu tinha de me colocar a serviço da humanidade. ${ }^{25}$ (WINTERSON, 2019, p.237)

A sua grande contribuição para a humanidade seria, portanto, a fabricação de robôs mulheres que se renderiam às masculinidades dominantes e jamais ameaçariam a sexualidade ou posição de poder de um homem. No evento da Royal Academy, Ron apresenta os diversos modelos de sexbots - há até um modelo feminista da década de 1970 - e explica que não tem nada contra as mulheres não ficarem mais em casa, pois elas "não são peixes dourados. Elas evoluíram. Mas, como diz a minha mãe, a emancipação pode ser um problema para um homem." ${ }^{26}$ (p.38) O público de Ron é diverso: mulheres demasiadamente ocupadas com suas carreiras que alugam as sexbots para seus maridos, professores universitários, homens jovens e idosos, masoquistas.

O empreendedor chegara a cogitar a fabricação de um robô coroinha para distribuir nas igrejas católicas a fim de evitar que padres abusassem dos meninos, mas a pesquisa de mercado mostrou que isso não seria vantajoso. Porém, com a ajuda da evangélica Claire, que passa a ser sua namorada e sócia, Ron inicia a produção da Companheira Cristã, uma sexbot para "os

25 "I saw armies of lonely men walking along a ruined road. Men with their heads bowed and their handsA in their pockets. Nobody was talking. Each one walked alone. Then, coming towards the men, suddenly, down the same ruined road, were all these beautiful girls. Girls who would never get old or ill. Girls who would always be saying yes and never saying no.

And in the sky there was the moon, big as a Bitcoin, and I knew I had to put myself at the service of humankind" (grifo no original).

26 "[...] women aren't goldfish. They've evolved. But, like my mum says, emancipation can be a problem for a man." 
missionários, para o viúvo, para o menino tentado pela carne"27 (p.238). Após muita discussão, Claire e Ron decidem manter o padrão de três buracos na Companheira Cristã, pois "o uso individual depende do indivíduo."28 (p.263)

O uso das sexbots e os personagens de Claire e de Ron revelam a discrepância existente entre a sociedade não-binária que Stein vislumbra com o avanço da inteligência artificial e as normas vigentes de gênero e sexualidade. Apesar das críticas feministas às sexbots, que são vociferadas por mulheres como a jornalista Polly D. e pelo médico transgênero Ry, o empresário misógino insiste que o seu mercado é, de fato, sustentado pela masculinidade dominante. Quando Ry questiona se Ron já pensou em fazer robôs homens, ele responde que a própria anatomia do corpo masculino impede tal empreendimento porque "basicamente um robô-menino é um vibrador anexado a um corpo", o que não permite que o sexbot "coma ela por trás. Ela tem de sentar-se nele", estragando a diversão "do banho de banheira, as velas, as suas músicas preferidas [...]. As coisas que as mulheres gostam para elas entrarem no clima"29 (p.48). Os estereótipos de gênero são, para Ron, insuperáveis, mesmo com o avanço tecnológico e isso também sobressai quando ele descobre que Ry é trans: ainda que tenha a aparência de um homem, Ron não aceita a sua masculinidade devido à ausência de um pênis em seu corpo.

A figura de Ry no romance é relevante justamente pelo seu

27 "For the missionary, for the widower, for the boy tempted by the flesh."

28 "Individual use is up to the individual."

29 "Basically a boy-bot is a vibrator wih a body attached. [...] He can't shunt her from behind. She has to sit on him [...] No fun when you've had the bath, the candles, all your favorite songs [...]. The things women like to get them in the mood." 
significado do duplo masculino-feminino no mesmo corpo: "Eu sou o que sou, mas o que sou não é somente uma coisa, um gênero. Eu vivo com o duplo." ${ }^{\prime 30}$ (p.89). Victor Stein apaixona-se por Ry pelo fato de ele ter "escolhido intervir na sua evolução" e ter acelerado "o seu portfólio de possibilidades." ${ }^{\prime \prime 1}$ (p.154). Ry não se sentia confortável em seu corpo como mulher e, portanto, decidiu realizar a cirurgia para retirar as mamas e submeter-se a tratamento hormonal. No entanto, ele nunca quis colocar um pênis e preferiu manter a sua vagina. Ry só é visto com normalidade por Stein, pois Ron e Claire o consideram uma aberração e a jornalista Polly D., como um ser exótico, ainda que ela demonstre interesse sexual pelo médico.

Se as ideias tecnológicas e transumanistas de Stein parecem abrir caminho para garantir a Ry uma vida "normal", na qual ele não deve se preocupar com a transfobia, o mundo real no qual ele vive o faz lembrar constantemente da ameaça que causa o seu corpo. Quando Ry sai para um bar com Claire e Ron, ele é brutalmente estuprado por um homem no banheiro masculino quando este descobre que ele tem uma vagina: aquela "não era a primeira vez. Não será a última. E eu não denuncio porque não suporto os olhares maliciosos e debochados e os medos da polícia. Também não suporto a presunção de que a culpa é minha." ${ }^{\prime 32}$ (p.244).

O sofrimento de Ry e os obstáculos impostos pela transfobia não o convencem de que um futuro pós-humanista seja a solução, o que provoca ceticismo e medo por parte de Ry em relação aos

30 "I am what I am, but what I am is not one thing, not one gender. I live with doubleness." 31 "You chose to intervene in your evolution. You accelerated your portfolio of possibilities."

32 "This isn't the first time. It won't be the last. And I don't report it because I can't stand the leers and jeers and fears of the police. And I can't stand the assumption that somehow I am the one at fault." 
experimentos de Stein. Por um lado, ele entende que pode haver uma disjunção entre a mente e o corpo, tendo ele mesmo passado por esta situação enquanto era mulher. Por outro, Ry demonstra desconfiança na premissa de Stein de que a consciência possa ser completamente separada do corpo, pois a própria existência humana como sujeito, segundo ele, depende da experiência corporal do indivíduo em seu meio social. Esta posição reverbera as próprias teorias da performatividade de Judith Butler, pelas quais a filósofa afirma que a identidade sexual e de gênero de um indivíduo ganha materialidade pela repetição involuntária das normas sociais que definem o masculino e o feminino, heterossexualidade e homossexualidade dentro de um contexto histórico e social (cf. BUTLER, 1993, p.93-111).

Em contrapartida ao personagem de Ry, que se apresenta como um corpo não-binário - "agora masculino, agora nem tanto, agora claramente uma mulher que vai deslizar dentro do corpo de um menino"33 (WINTERSON, 2019, p.298) -, as sexbots fabricadas por Ron Lord representam a feminilidade hiperssexualizada, muito explorada pela indústria pornográfica masculina e heterossexual. Apesar das diferentes percepções, Ron e Ry demonstram receio em relação aos experimentos de Stein, ainda que Ron possa se beneficiar do desenvolvimento robótico do cientista para o aprimoramento de suas sexbots.

De forma irônica, é Ron que apresenta questionamentos éticos sobre as pesquisas desenvolvidas pela empresa Alcor com o congelamento de humanos e sobre o seu objetivo de eliminar a morte. Quando o CEO Max More explica a possibilidade de trazer 33 "Now male, now not quite, now quite clearly a woman who will slip inside a boy's body" 
de volta à vida aqueles que já morreram, Ron imediatamente pergunta, "Nós não iríamos querer que todos eles voltassem, certo?"34 (p.226) e questiona os critérios para a decisão de quem poderia viver eternamente ou não: "Imbecis assassinos, pedófilos, ladrões, loucos, aquele cara no Brasil - Bolsonaro. E se você tivesse a cabeça do Hitler aí dentro?" ${ }^{\prime 35}$ Além disso, Ron manifesta dúvidas de ordem jurídica: "Você bate as botas. Todos os seus parentes gastam o seu dinheiro, aí bingo! Você está de volta. E aí?"36 (p.227) As indagações de Ron, que representa o homem branco comum, refletem os impasses éticos e morais que estariam em jogo caso os experimentos de Stein obtenham sucesso, pois não há estrutura jurídica, social e política para a tomada das decisões em questão.

Se a ficção científica distópica "contém um elemento de alerta para o futuro, baseado na extrapolação de tendências do presente ${ }^{\prime 37}$ (ALDRIDGE, 1978, p.65), Frankissstein manifesta as inquietações do nosso presente, que claramente nos traz lembranças do passado histórico e aponta para incertezas do futuro. Winterson não expressa otimismo com os desenvolvimentos científicos e tecnológicos que, muitas vezes, são vistos como progresso na sociedade. Um exemplo é a perspectiva de Halberstam e Livingston (1995) sobre o póshumanismo, que projeta a incorporação tecnológica no corpo humano como uma maneira de superar as dicotomias binárias que determinam as identidades sexual e de gênero. É claro que 34 "We wouldn't want them all back though, would we?" (Grifo no original) 35 "Murdering bastards, child molesters, thugs, nutters, that bloke in Brazil - Bolsonaro. What if you had Hitler's head in a bag there?"

36 "You drop dead. All the relatives spend your money, then bingo! You're back. Than what?"

37 "[Dystopic science fiction] contains an element of future warning, based on extrapolations of present trends." 
as possibilidades de transição para sujeitos transgênero são um grande mérito da ciência. Porém, a questão levantada pelo romance de Winterson vai além da disponibilidade de tecnologias científicas: as estruturas sociais, como elas existem, estão aptas a lidar com esses avanços? Como a própria autora afirma em uma entrevista para o Los Angeles Times, "Nós somos demônios e anjos. Nós inventamos coisas - nós dividimos o átomo e o que fazemos? Nós fazemos uma bomba"38 (WINTERSON Apud KELLOGG, 2019, s/p).

\section{CONCLUSÃO}

Frankissstein reproduz temáticas presentes nas obras anteriores de Winterson, como a materialidade do corpo, o amor como um sentimento conturbado e virtuoso, o desejo e a sexualidade. No romance, a autora recorre a estratégias narrativas já consolidadas em sua literatura, que constantemente se utiliza da intertextualidade, da fusão de gêneros literários e da nãolinearidade temporal. No entanto, o entrelaçamento do gótico com a ficção científica e a distopia é um experimento inédito no conjunto de obras da autora, tendo em vista que o gótico só havia sido explorado em The Daylight Gate (2005) e a ficção científica e distopia, em The Powerbook (2001) e em The Stone Gods (2007).

A temporalidade de Frankissstein é articulada pela mistura do passado e do futuro, que são evocados para construir o presente. Por um lado, há repetidas referências textuais históricas e culturais, como excertos de Frankenstein, da recepção de Frankenstein, da descrição de Bedlam produzida pelo viajante César-François de 38 "We are devils and angels. We invent things - we split the atom and what do we do? We make a bomb." 
Saussure e até mesmo um trecho da música "Take it Easy" da banda Eagles. Essas referências nem sempre são atribuídas às suas publicações originais, embora sejam quase sempre grifadas. Por outro lado, as projeções futurísticas que envolvem inteligência artificial, pós- e transumanismo implicam pesquisas que ainda estão em desenvolvimento e as possibilidades de futuro que podem, de fato, trazer vantagens, mas que, se usadas de forma antiética, podem transformar o mundo em pesadelo.

As alusões ao passado sugerem uma noção de imortalidade e de continuidade histórica, esta última sublinhando como algumas apreensões e normas do passado ainda estão vigentes no presente. As falas misóginas de Ron Lord, o uso oportunista da religião pela evangélica Claire e o estupro de Ry são episódios que reverberam a força das estruturas sociais que foram reproduzidas ao longo da história e que sustentam a dominância do machismo, da propagação da religião como forma de alienar e controlar, da homofobia e da transfobia. Do mesmo modo, as discussões sobre o avanço e os perigos da ciência e da tecnologia, como já haviam sido tratadas no romance de Mary Shelley, suscitam dúvidas sobre o preparo das sociedades e de seus governos para lidar com essas mudanças que já estão no horizonte, mas que ainda não foram implementadas. Enquanto bilionários investem na colonização de Marte e no congelamento de seus corpos em Alcor, a destruição, a desigualdade e o autoritarismo ainda são traços marcantes do atual cenário político e social, o que confirma o ceticismo na crença do desenvolvimento e avanço científico e tecnológico como uma possível salvação para a humanidade. 


\section{REFERÊNCIAS}

ALDRIDGE, Alexandra (1978). The Scientific World View in Dystopia. 2.ed. Ann Arbor: University of Michigan Press.

BOSTROM, Nick (2005). "In Defense of Posthuman Dignity". Bioethics, 19(3), 202-214.

BLOOM, Harold (2007). Mary Shelley's Frankenstein. New York: Infobase Publishing.

BYERS, Sam (2019). "Frankissstein by Jeanette Winterson review: a dazzling animation of Shelley's novel". The Guardian. In https://www.theguardian. com/books/2019/may/24/frankissstein-jeanette-winterson-review Acesso em 10.Jan.2019.

BUTLER, Judith (1993). Bodies that Matter: on the Discursive Limits of Sex. New York: Routledge.

CARTWRIGHT, Amy (2005). The Future is Gothic: Elements of Gothic in Dystopian Novels. (Tese - Doutorado). Universidade de Warwick.

CHARLES, Ron (2019). 'In 'Frankissstein', Jeanette Winterson brings something zany and intellectual ALIVE!" The Washington Post. In https:// www.washingtonpost.com/entertainment/books/in-frankissstein-jeanettewinterson-brings-something-zany-and-intellectualalive/2019/10/14/fae88b7aee87-11e9-89eb-ec56cd414732_story.html Acesso em 10.Jan.2019.

CLAEYS, Gregory (2010). "The Origins of Dystopia: Wells, Huxley and Orwell". In: (Ed.). The Cambridge Companion to Utopian Literature. Cambridge: Cambridge University Press, p.107-131.

HALBERSTAM, Judith; LIVINGSTON, Ira (Eds.) (1995). Posthuman Bodies. Bloomington and Indianopolis: Indiana University Press.

HALL, Melinda (2017). The Bioethics of Enhancement: Transhumanism, Disability and Biopolitics. London: Lexington Books.

HARAWAY, Donna (2006). "A Cyborg Manifesto: Science, Technology and Socialist-Feminism in the Twentieth Century". In: STRYKER, Susan; WHITTLE, Stephen (Eds.) The Transgender Studies Reader. New York, London: Routledge, p.103-118. 
JAGOSE, Annamarie (1996). Queer Theory: an Introduction. 2.ed. Melbourne: Melbourne University Press.

KELLOGG, Carolyn (2019). "Frankissstein author Jeanette Winterson gives new life to the monster". Los Angeles Times. In https://www.latimes.com/ entertainment-arts/books/story/2019-10-10/frankissstein-jeanette-winterson Acesso em 10.Jan.2019.

MEIKLE, James; BOSELEY, Sarah (2010). "MMR row doctor Andrew Wakefield struck off register". The Guardian. In https://www.theguardian.com/society/2010/ may/24/mmr-doctor-andrew-wakefield-struck-off Acesso em 12.Jan.2020.

PEARSON, Wendy Gay; HOLLINGER, Veronica; GORDON, Joan (Eds.) (2008). Queer Universes: Sexualities in Science Fiction. Liverpool: Liverpool University Press.

SANTAELLA, Lucia (2007). "Pós-humano: por quê?". Revista USP, 74, 126-137.

SHELLEY, Mary (2003). Frankenstein, or the Modern Prometheus. London: Penguin Books.

SHEPPARD, Elena (2019). “Reanimating 'Frankenstein': Jeanette Winterson's 'Frankissstein'". The Los Angeles Review of Books. In https://lareviewofbooks. org/article/reanimating-frankenstein-on-jeanette-wintersons-frankissstein/ Acesso em 10.Jan.2019.

SMITH, Andrew (2007). Gothic Literature. Edinburgh: Edinburgh University Press. WILLIAMS, Holly (2019). "Frankissstein by Jeanette Winterson review: Bringing Mary Shelley's Classic into the modern world". The Independent. In https:// www.independent.co.uk/arts-entertainment/books/reviews/frankisssteinreview-jeanette-winterson-book-frankenstein-mary-shelley-a8924916.html Acesso em 10.Jan.2019.

WINTERSON, Jeanette (1987). The Passion. 2.ed. London: Penguin Books. (1989). Sexing the Cherry. 10.ed. London: Vintage. (1992). Written on the Body. London: Jonathan Cape. (2001). The Powerbook. 12.ed. London: Vintage. (2005). The Daylight Gate. 8.ed. London: Hammer. (2007). The Stone Gods. 2.ed. London: Penguin Books. (2019). Frankissstein. London: Jonathan Cape. 